\title{
Voltage-Dependent Nonlinearities in the Membrane of Locust Nonspiking Local Interneurons, and Their Significance for Synaptic Integration
}

\author{
Gilles Laurent ${ }^{\mathrm{a}}$ \\ Department of Zoology, University of Cambridge, Cambridge CB2 3EJ, England
}

Some aspects of the electrotonic and active membrane properties of nonspiking local interneurons were studied in isolated locust thoracic ganglia, using the switched currentand voltage-clamp techniques in neuropilar recordings. The average transmembrane potential $\left(V_{r}\right)$ of the interneurons was $-58 \pm 6 \mathrm{mV}(n=85)$, and the input resistance (in the linear region of the current-voltage curve) was $16.5 \pm 8 \mathrm{~m} \Omega$ ( $n=19$, range 8 to $32 \mathrm{M} \Omega$ ). The membrane and equalizing time constants were estimated from charging curves evoked by the injection of low density hyperpolarizing current pulses from about $-80 \mathrm{mV}$, i.e., from voltages in the linear region of the $I V$ curve. The curves yielded 2 time constants $\left(\operatorname{tau}_{\mathrm{m}}\right.$ and $t u_{1}$ ) whose average values were $33.2 \pm 9$ msec and 3.3 $\pm 1 \mathrm{msec}(n=18)$, respectively. The mean specific membrane resistance is therefore about $33 \mathrm{k} \Omega \cdot \mathrm{cm}^{2}$, assuming that the membrane capacitance is ca. $1 \mu \mathrm{F} \cdot \mathrm{cm}^{-2}$. An outward rectification was always observed upon depolarization from potentials more negative than $V_{r}$ and was accompanied by a decrease in input resistance and membrane time constant. The "resting" membrane, for example, had a time constant of $26.4 \pm 8 \mathrm{msec}(n=31)$. This outward rectification was due to at least 2 conductances with different inactivation kinetics, similar to the transient "A" and "delayed-rectifier" potassium conductances. No inward rectification was ever observed upon injection of hyperpolarizing current. In about $60 \%$ of the recordings, an active and TTX-resistant depolarizing process could be evoked by rapid depolarization around $V_{r}$. The voltage-dependent properties of the membrane of the nonspiking local interneurons had dramatic effects on the shape and time course of natural or evoked unitary PSPs. The half-width of EPSPs, for example, decreased by a factor of 7.5 if the membrane potential was shifted from -93 to $-50 \mathrm{mV}$. When the membrane potential of an interneuron was altered with a triangular current waveform, the reduction of tonically occurring IPSPs depended more on the sign and rate of the induced voltage change than on the absolute transmembrane potential. For 2 iden-

Received Jan. 8, 1990; revised March 5, 1990; accepted March 6, 1990.

I am grateful to the Royal Society, the S.E.R.C. (UK), and the Hasselblad Foundation for their generous support during the course of this work. The support from N.I.H. (USA) grant NS16058 to Malcolm Burrows is also gratefully acknowledged. Many thanks are due to Malcolm Burrows, Nigel Emptage, Roger Hardie, Philip Newland, and an anonymous referee for their numerous helpful comments on the manuscript.

${ }^{a}$ Correspondence should be addressed to Dr. Gilles Laurent at his present address: California Institute of Technology, Biology Division, 156-29, Pasadena, CA 91125 .

Copyright (C) 1990 Society for Neuroscience $0270-6474 / 90 / 072268-13 \$ 03.00 / 0$ tical instantaneous values of membrane potential, for example, the reduction of the PSPs was greater during the depolarizing phase than during the hyperpolarizing phase of the current waveform. The possible nature of the active membrane conductances underlying the nonlinear electrical behavior of the membrane is discussed, together with their functional significance for local circuit synaptic integration.

An understanding of information processing in multilayered neuronal networks requires knowledge of the precise patterns of connections between the various component neurons and of the input-output transformation accomplished by each neuron or neuronal layer. This transformation itself depends on the characteristics of the transfer at each synapse and on the intrinsic membrane properties of the intervening neurons. Two connected neurons, such as amacrine and ganglion cells in the retina (Sakuranaga and Naka, 1985), inferior olivary neurons and Purkinje cells in mammalian cerebellum (Llinás and Sugimori, 1980; Llinas, 1988), pyramidal and stellate neurons in mammalian neocortex (McCormick et al., 1985), or spiking and nonspiking local interneurons in the insect CNS (Pearson and Fourtner, 1975; Burrows and Siegler, 1976, 1982) can use radically different integrative processes, such as, for example, graded and spike-mediated synaptic transmission or oscillatory and "linear" membrane behavior. Some knowledge of the membrane properties of any given class of neuron in a network is thus essential to understand the overall integrative processes this network performs.

The local circuits responsible for sensory-motor integration in the locust thoracic ganglia are known in considerable detail. A small number of spiking and nonspiking local interneurons receive afferent information from many thousand mechanoreceptors on the legs, and from it, form an appropriate reflex motor output (Burrows and Siegler, 1982; Siegler and Burrows, 1986; Burrows et al., 1988; Laurent and Burrows, 1988). The description and understanding of these circuits has reached the stage where the effect of a particular sensory stimulus on a given pool of motor neurons can be explained by the action and connections of the interposed interneurons (Siegler, 1984; Siegler and Burrows, 1984; Burrows, 1989; Burrows and Laurent, 1989). Nonspiking local interneurons, for example, receive spike-mediated inputs from mechanosensory afferents (Burrows et al., 1988; Laurent and Burrows, 1988), spiking local interneurons, (Burrows, 1987), and intersegmental interneurons (Laurent and Burrows, $1989 \mathrm{a}, \mathrm{b}$ ), and graded inputs from other nonspiking local interneurons (Burrows, 1979b). In turn, they control pools of motor neurons (Burrows and Siegler, 1976, 1978) and appear 
to play a critical role in the central control of the sensorimotor pathways (Burrows et al., 1988; Laurent and Burrows, 1989b).

The integrative properties of the individual neurons, however, are less well understood. In particular, it is intriguing that one class of local interneurons in these circuits uses spikes while a second uses only graded potentials as intra- and intercellular signals (Burrows and Siegler, 1976, 1982). These 2 classes of interneurons are also structurally different in that the spiking ones are almost functionally polarized (Watson and Burrows, 1985), whereas the nonspiking ones have extensively intermingled input and output synapses (Watson and Burrows, 1988), allowing, in principle, local "dendritic" processing to occur. Moreover, particular local afferent inputs that a nonspiking interneuron receives can be specifically shunted postsynaptically by inputs from some intersegmental interneurons, but not by others (Laurent and Burrows, 1989b). It thus appears that intrinsic electrical properties of the membrane, on the one hand, and the distribution of synapses, on the other, could generally provide nonspiking interneurons with important integrative properties. Graded, decremental processing in cholinergic amacrine cells of the vertebrate retina, for example, could explain why these neurons appear to have smaller receptive fields than their widespread arborizations would suggest (Masland et al., 1984). Neighboring pre- and postsynaptic terminals on the dendrites of lateral geniculate nucleus interneurons in the cat may allow local and independent computations that are "invisible" to the soma (Bloomfield and Sherman, 1989). In addition, the synaptic transfer at nonspiking synapses relies on only small presynaptic depolarizations (Graubard, 1978; Burrows, 1979a; Blight and Llinás, 1981). The synaptic transfer of the information contained in a barrage of summating EPSPs is thus possible and should be different from that which results from a train of action potentials at a spiking synapse.

Understanding the function, peculiarities, and possible advantages of nonspiking integration in local circuits, where both action potentials and graded signals are used in parallel, is thus the aim of the study undertaken here. In this paper, I shall describe the passive and some active (voltage-dependent) membrane properties of nonspiking local interneurons, first to provide an assessment of their clcctrical geometry. I will then show that, although nonspiking, the membrane of these interneurons possesses several voltage-dependent nonlinearities, which have significant consequences for local synaptic integration.

\section{Materials and Methods}

Experiments were performed on adult locusts Schistocerca gregaria (Forskal) of both sexes. The results were gathered from 208 intracellular recordings of nonspiking local interneurons in 94 animals. All the results reported here come from experiments that were repeated from 4 to 41 times.

The preparation. Some experiments were performed in the intact animal, using the procedures designed by Hoyle and Burrows (1973). Ninety percent of the intracellular recordings were, however, made from a new preparation of an isolated nervous system, prepared as follows. The meso- and metathoracic sterna were removed, and the underlying ganglia exposed. The thoracic cavity was then immediately perfused with fresh locust saline, at room temperature. Care was taken not to damage the tracheal supply to the ganglia. The peripheral nerves from the meso- and metathoracic ganglia and the promeso- and metaabdominal connectives were cut as far from the ganglion as possible. Then the ventral longitudinal tracheae were cut to isolate the meso- and metathoracic ganglia, with as much of the extensive tracheae and air sacs supplying them as possible remaining. The isolated ganglia were then transferred to a small dish and pinned down, dorsal surface up, through perineural connective tissue onto Sylgard. The dorsal surface of the metathoracic ganglion was treated with $1 \%(\mathrm{wt} / \mathrm{vol})$ protease (Sigma type XIV) for $30 \mathrm{sec}$ and the saline was thoroughly washed. The isolated ganglia were then superfused with oxygenated saline containing $34 \mathrm{gm}$ liter ${ }^{-1}$ sucrose at room temperature, just to cover the 2 ganglia. The left and right longitudinal metathoracic tracheae, generally closed by surface tension forces, were then gently teased open at the surface of the saline. The preparation remained healthy for at least $2 \mathrm{hr}$.

Electrophysiology. Intracellular recordings were made from the neuropilar processes of nonspiking local interneurons using an Axoclamp$2 \mathrm{~A}$ (Axon Instruments) amplifier and thick-walled glass microelectrodes filled with $3 \mathrm{~m} \mathrm{~K}$ acetate or, in some experiments, with Lucifer yellow (Stewart, 1978) (electrode DC resistance: $40-70 \mathrm{M} \Omega$ ). The stray capacitance to ground created by the electrolyte/glass wall/saline interfaces was reduced by coating the electrode tips with Sylgard 184 (Dow Corning Co., Midland, MI, USA), and lowering the saline level to a minimum. These 2 precautions were indispensable to reduce the electrode time constant and allow switching rates greater than $2 \mathrm{kHz}$. Switched currentand voltagc-clamp rccordings ( $30 \%$ duty cycle) were then made, using the fastest switching rates allowed by the time constant of the electrode after optimal capacity compensation (see Wilson and Goldner, 1975; Merickel, 1980; Finkel and Redman, 1984). The true electrode voltage was monitored throughout the experiments on a separate oscilloscope, and switching rates between 4 and $6 \mathrm{kHz}$ were routinely obtained that allowed nearly complete electrode voltage decay before sampling. The interval between successive voltage samplings was always at least 6 and generally 10 times greater than the value for the electrode time constant. Under these conditions, $-3 /+3 \mathrm{nA}$ of current could be injected directly to ground in current-clamp mode, with no more than $\pm 2 \mathrm{mV}$ voltage drop across the electrode. Electrodes that did not pass this test were rejected. The output bandwidth of the amplifier was generally set at 1 $\mathrm{kHz}$. The saline temperature was constantly monitored and varied, in different experiments, between cxtremes of 20 and $29^{\circ} \mathrm{C}$. Voltage-clamp experiments were, for practical reasons, performed between 20 and $24^{\circ} \mathrm{C}$. The specific effects of temperature on the kinetics of the membrane currents and on rectification and synaptic integration were not studied here. In some experiments, extracellular recording and stimulation of mechanosensory afferents were performed using vinyl tip suction electrodes on intact (in nonisolated nervous systems) or sectioned peripheral nerves. Data were recorded on a Store-7-DS Racal FM tape recorder (frequency response flat to $5 \mathrm{kHz}$ ) and analyzed off-line on an ATcompatible microcomputer, after digitization at $10-15 \mathrm{kHz}$, using a CED1401 A/D-D/A interface with 2MB RAM (Cambridge Electronics Design). Stimulating pulse regimes for the voltage-clamp experiments were generated by a Master- 8 stimulator or by the microcomputer. Leak current subtraction was done digitally, using averaged templates obtained, with each interneuron, from corresponding hypcrpolarizing voltage steps. TTX was obtained from Sigma Chemical Co.

\section{Results}

\section{Identification of the nonspiking interneurons}

All recordings presented in this paper were made from the neuropilar branches of the interneurons and thus probably often from the larger processes, which are about $7-10 \mu \mathrm{m}$ in diameter (Watkins et al., 1985). Identification of the interneurons was based on the following established criteria (Burrows and Siegler, 1978):

1. A "resting" transmembrane potential $\left(V_{r}\right)$ of at least -45 $\mathrm{mV}$. The average transmembrane potential of the interneurons in these isolated preparations, and measured on withdrawal of the electrode, was $-58 \pm 6 \mathrm{mV}$ (mean $\pm \mathrm{SD}, n$ $=85$ interneurons).

2. The absence of action potentials upon large (up to $10 \mathrm{nA}$ ) and prolonged (several seconds) depolarizing current injections, cven after a preceding period of sustained hyperpolarization, to remove inward current inactivation.

3. A generally noisy synaptic background, even in a deafferented or isolated ganglion.

4. The responsiveness of the interneurons to mechanosensory stimulation of the leg (in intact animals).

5. The presence of leg motor effects upon de- and/or hyper- 

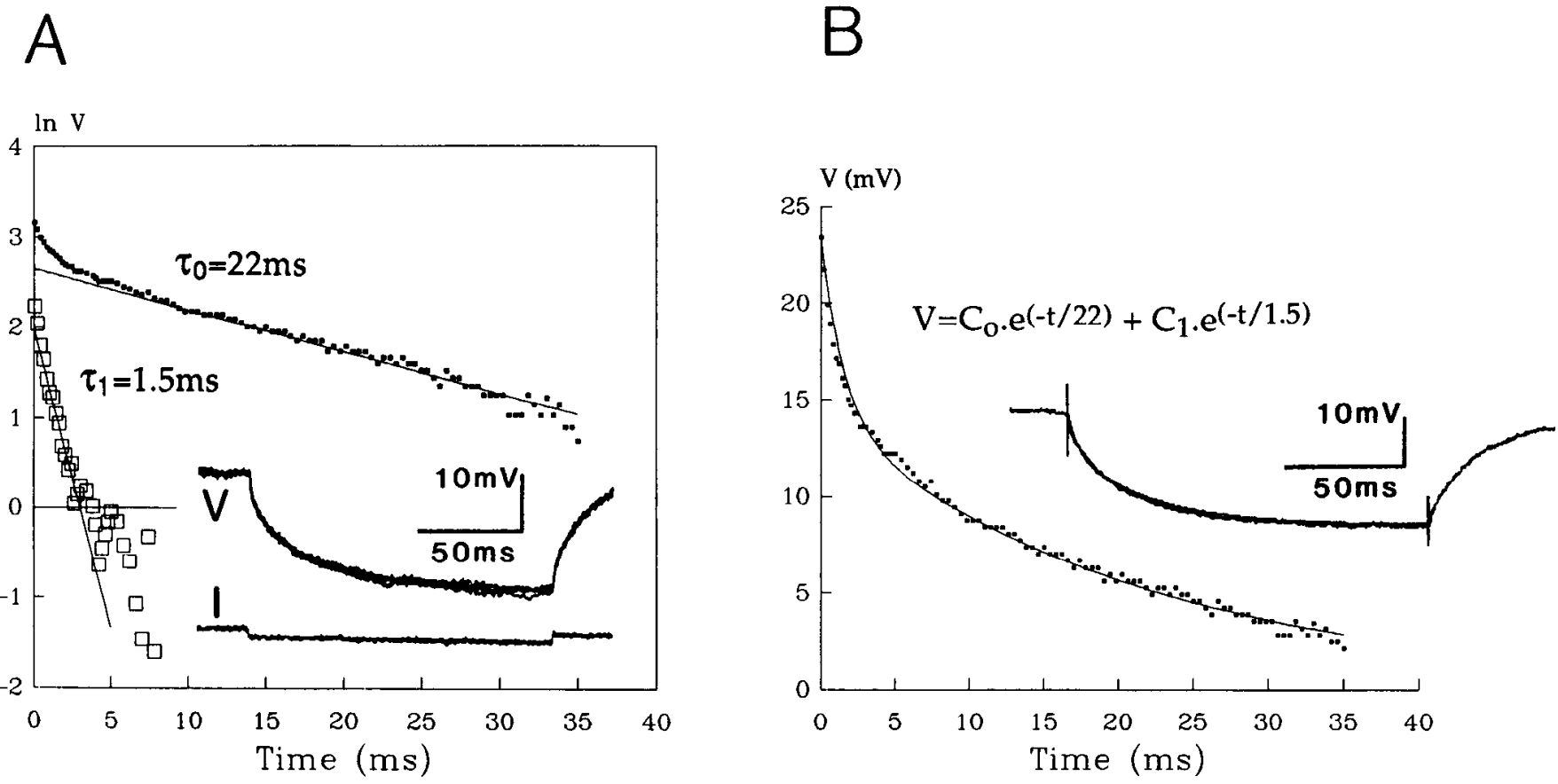

Figure 1. Methods used to determine the membrane time constants. $A$, Semilogarithmic plot of the first 35 msec of voltage decay, taken from the average of the data in inset. The charging function was well described by 2 exponential decays with time constants of 22 and 1.5 msec. The shorter time constant was determined by exponential "peeling." Inset, Four superimposed sweeps, showing the membrane voltage response ( $V$ ) to intracellular injection of $-1 \mathrm{nA}$ current $(I)$. The interneuron was here at a "resting" potential of $-55 \mathrm{mV} . B$, The data points in $A$ and the theoretical curve constructed from the values of the time constants (equation in inset) determined by exponential peeling have been superimposed. These time constants were then used as starting points for an iterative computer curve fitting program and refined. The original averaged data and the final fitting curve are superimposed between the 2 vertical cursors in inset. Note that the horizontal and vertical calibrations of the insets in $A$ and $B$ are slightly different.

polarization, and in the absence of action potentials in the interneurons.

6. Verification of the morphology of the interneurons, in several isolated preparations, by intracellular staining.

7. The absence of fast, unclamped inward currents upon depolarizing voltage steps in single-electrode voltage-clamp mode.

\section{Membrane and equalizing time constants}

To estimate the membrane time constant of the interneurons, small hyperpolarizing current steps were applied and the time course of the resulting voltage transients was analyzed (Fig. 1 $A$ ). In an ideal linear neuron model, such voltage transients can be described as the sum of an infinite number of exponential decays, with different time constants tau $\mathrm{u}_{\mathrm{i}}$ :

$$
V(t)=\Sigma C_{\mathrm{i}} \cdot \exp \left(-t / \operatorname{tau}_{\mathrm{i}}\right),
$$

where $0<\mathrm{i}<\infty$ and the $C_{\mathrm{i}}$ coefficients are time-independent (Rall, 1969). The larger time constant $\left(\operatorname{tau}_{0}\right)$ is the membrane time constant, or $\operatorname{tau}_{\mathrm{m}}$ if the membrane is in a passive state, and the shorter ones $\left(\operatorname{tau}_{i}\right.$, where $\left.i>0\right)$ are the equalizing time constants, which describe the passive charge redistribution to the nonisopotential regions.

In general, several (8-128) sweeps of the hyperpolarizing transients evoked by injection of small $(-0.3$ to $-1 \mathrm{nA})$ currents were averaged, and the average voltage trace was plotted on semilogarithmic coordinates. Only small currents were injected to try and limit the changes in membrane resistivity during the pulse. The initial $0.5 \mathrm{msec}$ of a current pulse was systematically ignored. A straight line was fitted by eye when possible, or with a least-squares linear regression method, and the larger time constant tau $\mathrm{u}_{0}$ was measured as the negative inverse of the slope. An exponential "peeling” (Rall, 1969, 1977) was then performed to determine any shorter time constants (Fig. 1 $A$ ). The data points in Figure $1 A$ are plotted again in Figure $1 B$ on linear coordinates and superimposed on the theoretical curve constructed from the 2 time constants determined by exponential peeling. These estimated values of tau $\mathrm{u}_{0}$ and of the smaller equalizing time constants ( $\operatorname{tau}_{1}$, where $\mathrm{i}>0$ ) were then used as starting points for an iterative computer curve fitting program and thus refined until the best fit was obtained. The original averaged data and the best fit are superimposed in Figure $1 B$ (inset). In none of the 31 analyzed interneurons could the membrane charging transient be fitted with a single exponential, but no more than 2 time constants could ever be isolated with confidence. The average values of $\operatorname{tau}_{0}$ and $\mathrm{tau}_{1}$, as measured from "resting" potential, were respectively $26.4 \pm 8 \mathrm{msec}(n=31)$ and $3.55 \pm 1.5 \mathrm{msec}(n=31)$.

The finding that rectification generally already occurs at potentials $10-20 \mathrm{mV}$ more negative than "resting" potential (see below and Fig. 2) indicated, however, that the resting membrane was unlikely to behave passively during the current pulses. The same experiments were thus repeated while holding the interneurons around $-80 \mathrm{mV}$, i.e., in the linear region of their current-voltage curve (Fig. $2 A$ ). In these conditions, $\operatorname{tau}_{0}$ increased to $33.2 \pm 9 \mathrm{msec}(n=18)$, whereas tau 1 at $3.3 \pm 1 \mathrm{msec}(n=$ 18) was little changed. From the latter value of $\operatorname{tau}_{0}$, probably closest to the passive membrane time constant, and from an assumed specific membrane capacitance of about $1 \mu \mathrm{F} / \mathrm{cm}^{2}$ (Cole, 
A

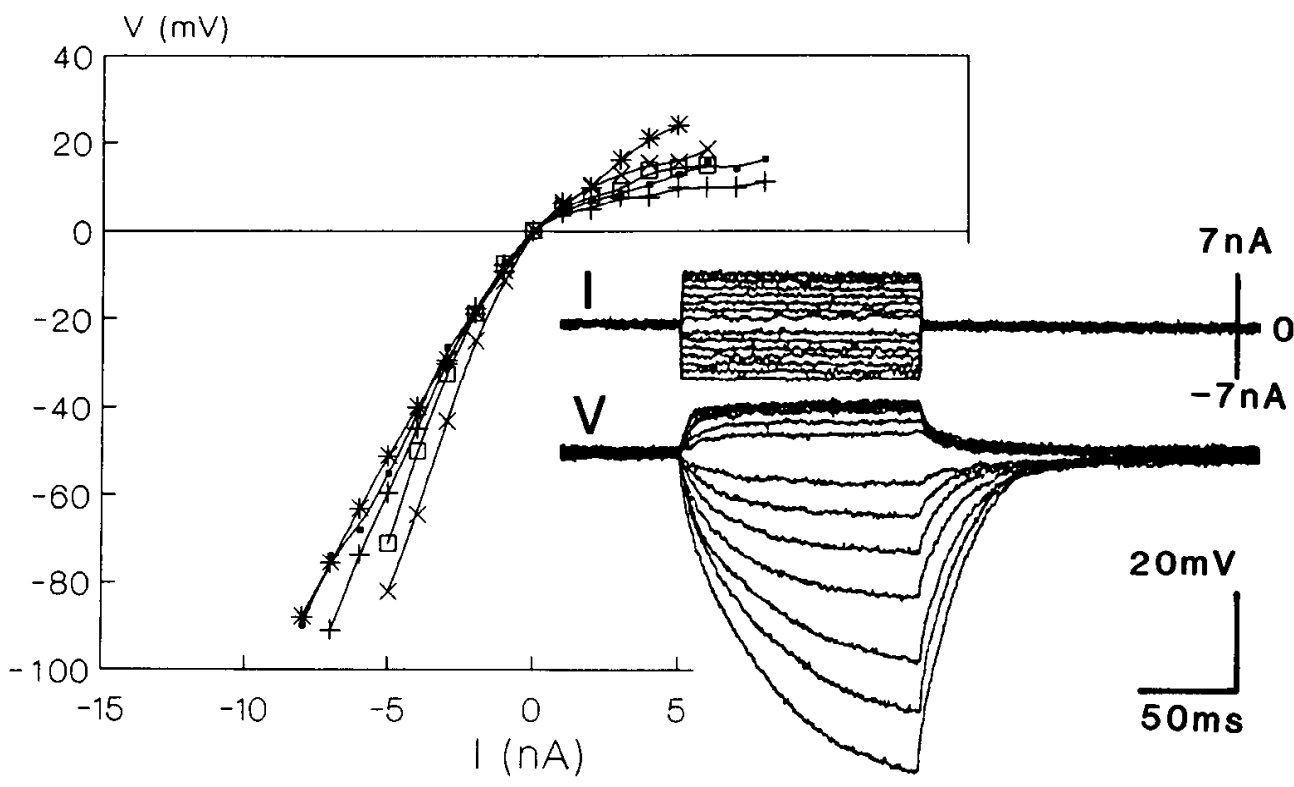

B

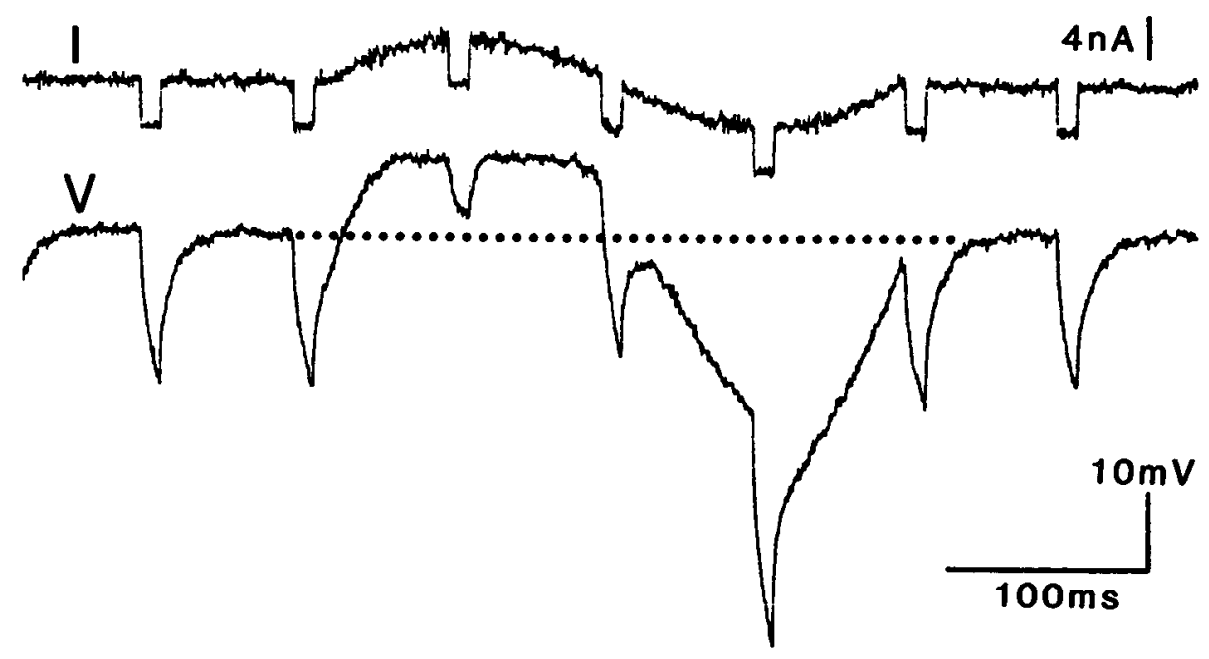

Figure 2. Outward rectification of the nonspiking interneuron membrane. $A$, Pulses of current were injected intracellularly in a neuropilar branch of the interneurons, using the switched current-clamp technique. The responses of one interneuron whose "resting" potential was $-55 \mathrm{mV}$ are shown in inset. A large outward rectification was observed upon depolarization. No voltage "sag" was observed on hyperpolarization. The current-voltage curves of 5 other nonspiking interneurons show the consistent outward rectification, starting at potentials more negative than rest $(V=0)$. $B$, Short test pulses of $-4 \mathrm{nA}$ arc injected cvery $150 \mathrm{mscc}$ in another nonspiking interneuron held at $V_{\mathrm{r}}=-58$ $\mathrm{mV}$. A slow current sinewave of $8 \mathrm{nA}$ peak-to-peak is then superimposed, and the changes in $R_{\mathrm{IN}}$ are observed. Although the membrane is little depolarized during the positive phase of the sinewave, the input resistance drops dramatically, to recover during the descending phase and increase during the hyperpolarization.
1968; Hille, 1984), the mean specific membrane resistance is deduced to be about $33 \mathrm{k} \Omega \cdot \mathrm{cm}^{2}$ (provided it is constant throughout the membrane).

\section{Outward rectification}

With hyperpolarizing currents greater than $-2 \mathrm{nA}$, the membrane potential increased nearly linearly with the applied current (Fig. 2A). No voltage "sag" suggestive of an inward rectification (Katz, 1949) was revealed. By contrast, with depolarizing currents of +1 or $+2 \mathrm{nA}$, signs of outward rectification were already apparent (Fig. 2A). With currents of $+3 \mathrm{nA}$, the membrane depolarized more rapidly and plateaued about $10 \mathrm{mV}$ above rest. Increasing currents resulted in little further depolarization. The current-voltage curves of 5 interneurons in Figure $2 A$ (all with "resting" potentials of -57 to $-53 \mathrm{mV}$ ) show the consistent outward rectification, which generally started from about
-80 to $-70 \mathrm{mV}$, i.e., $10-20 \mathrm{mV}$ more hypcrpolarized than "resting" potential. The average value of the input resistance, measured from the linear region of the $I-V$ curve, was $16.5 \pm$ $8 \mathrm{M} \Omega(n=19$ interneurons, range 8-32 $\mathrm{M} \Omega$ ).

The outward rectification was always accompanied by a large increase in input conductance, as monitored by short hyperpolarizing current test pulses (Fig. 2B). Hyperpolarization from "rest," by contrast, usually led to a decrease in input conductance (Fig. 2B), indicating that certain voltage-sensitive conductances are tonically activated at "resting" potential. Furthermore, hyperpolarizing pulses delivered from voltages between $-85 \mathrm{mV}$ and $-36 \mathrm{mV}$ revealed that the charging and discharging transients were not symmetrical at potentials more negative than $-65 \mathrm{mV}$ (the repolarization being much slower), suggesting the activation of a hyperpolarizing conductance by depolarization (Fig. $3 A$ ). The time constant of repolarization, 

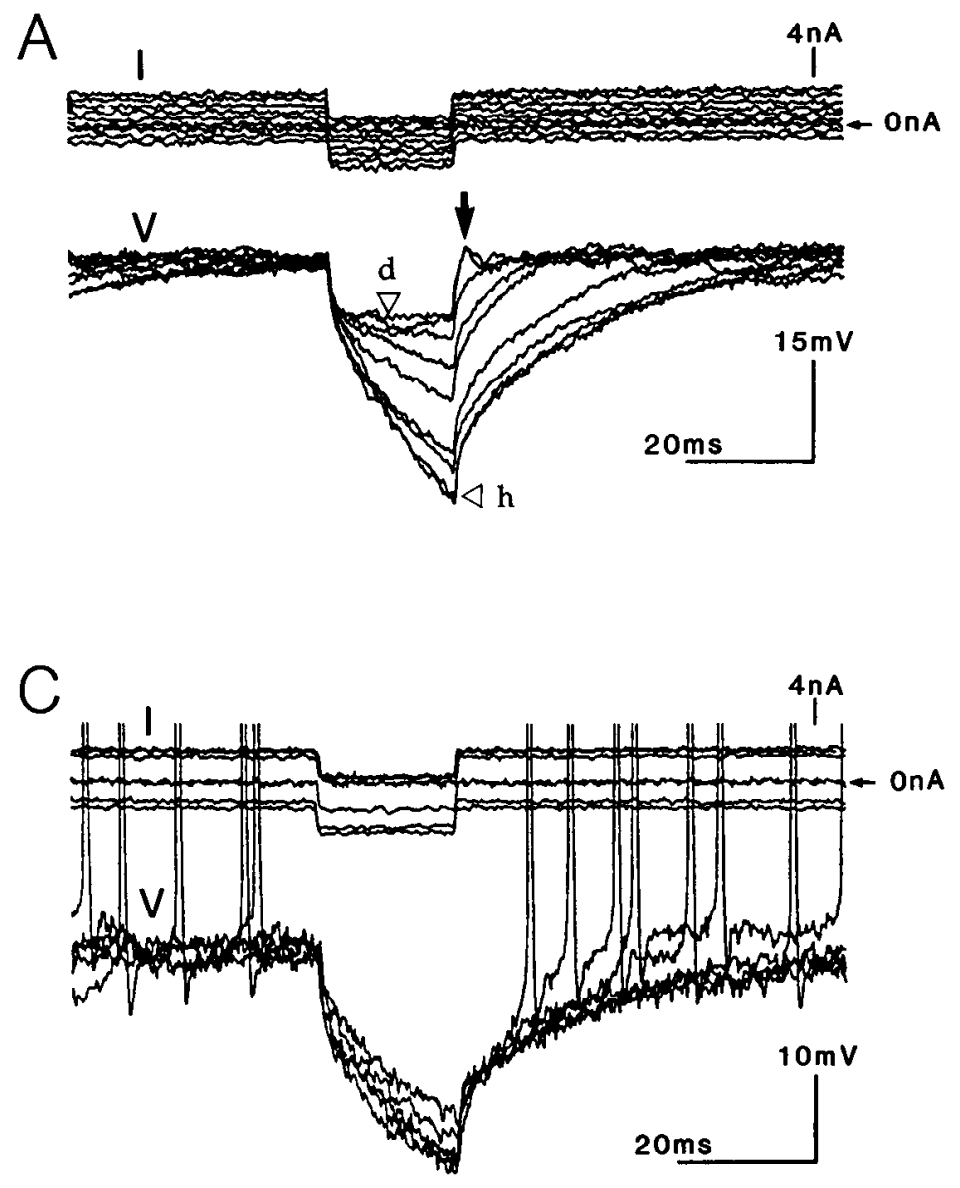

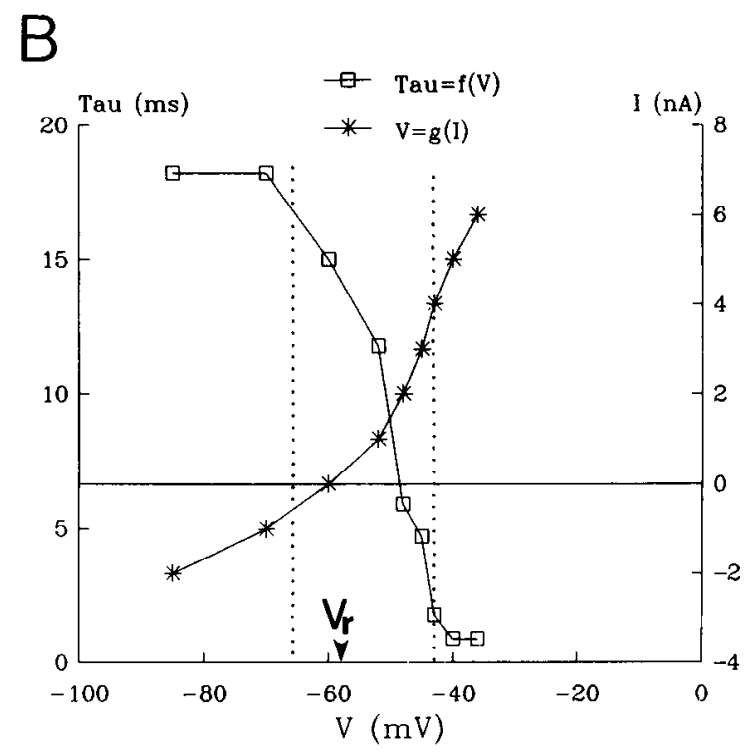

Figure 3. Voltage dependence of $R_{\mathrm{IN}}$ and tau $\mathrm{u}_{0} . A, \mathrm{~A}-4 \mathrm{nA}$ current pulse is applied to an interneuron, between holding voltages of -85 and -36 $\mathrm{mV}$. The time at which the voltage traces have been aligned is at the start of each current pulse. Note the change in membrane time constant and $R_{\mathrm{IN}}$ as the initial potential changes, the active depolarization (arrow) at the end of the pulse at the most depolarized holding voltages (d), and the slow membrane discharge at the most hyperpolarized holding potentials $(h) . B$, The time constant of decay of the discharging phase in $A$ (tau) is plotted against the initial membrane voltage (V). Tau was taken to be the larger time constant for all the excursions with multiexponential decays, i.e., all but the 2 excursions at the most depolarized voltages. For these 2 nonexponential curves, the time to $65 \%$ of the peak was taken. The current-voltage curve of this interneuron is superimposed. Note that the average "resting" potential $\left(V_{\mathrm{r}}\right)$ of the nonspiking interneurons lies in the steep region of the sigmoid curve. The voltage range between stippled lines is the operating range of the interneurons. $C$, The same experiment as in $A$ was repeated, in the same animal and with the same electrode, in a spiking neuron, to show the contrasting minor dependence of input resistance and membrane time constant on initial voltage. The action potentials have been clipped. The resting potential of this interneuron is $-69 \mathrm{mV}$.

plotted against initial voltage in Figure $3 B$, varied by a factor of 10 over $30 \mathrm{mV}$. The "resting" potential of the nonspiking interneurons, at $-58 \mathrm{mV}$, thus lies near the steepest region of the curve (Fig. 3B). Similar experiments performed on spiking neurons with more negative operating ranges showed that, by contrast, the time course of membrane transients upon the same amount of injected current varied very little between initial voltages of -93 and $-53 \mathrm{mV}$ (Fig. $3 C$ ). This suggests that the rectifying conductances have different activation ranges in these spiking and nonspiking neurons.

The outward currents activated by depolarization were examined in the nonspiking interneurons, using the single-electrode voltage-clamp technique. Figure $4 A$ illustrates the membrane responses to long depolarizing and hyperpolarizing voltage stcps delivered from a holding potential of $-80 \mathrm{mV}$. The membrane behaved linearly from -170 to $-80 \mathrm{mV}$, but outward currents appeared and grew nonlinearly from $-70 \mathrm{mV}$ (Fig. 4, $A, B)$. These currents consisted of at least 2 components: an early and rapidly inactivating current $\left(I_{\text {carly }}\right.$, Fig. $\left.4 A\right)$, followed by a sustained one, which never inactivated completely, even after $3 \sec \left(I_{\text {late }}\right.$, Fig. $\left.4 A\right)$. The total peak currents at $3 \mathrm{msec}$ and
$3 \mathrm{sec}$ were plotted as functions of the true voltage in Figure $4 B$, to show the contribution of the leak, early, and late components to the voltage-gated conductance increase. The early component reached its peak within $2-3 \mathrm{msec}$ and inactivated to $30 \%$ of its peak value within $15-35 \mathrm{msec}$ (Fig. $4 \mathrm{C}$ ). The voltage-sensitive outward currents thus resemble the so-called transient " $A$ "current (Hagiwara et al., 1961; Connor and Stevens, 1971) and the delayed-rectifier current. The detailed description of these currents will be the subject of a following publication.

\section{Frequency response}

To study the frequency response and putative filtering properties of the nonspiking membrane and their dependence on membrane potential, an approximation of the dynamic impedance of the interneurons was studied as a function of transmembrane voltage. A sinusoidal current ( $2 \mathrm{nA}$ peak-to-peak) at frequencies varying from 0.5 to $100 \mathrm{~Hz}$ was delivered to an interneuron (Fig. $5 \mathrm{~A}$ ) and the ratio of peak-to-peak voltage to peak-to-peak current was plotted as a function of frequency, for 3 initial membrane potentials $(-85 \mathrm{mV},-65 \mathrm{mV}$, and $-55 \mathrm{mV})$. The normalized data showed that the corner frequency $F_{\mathrm{c}}$ (frequency 

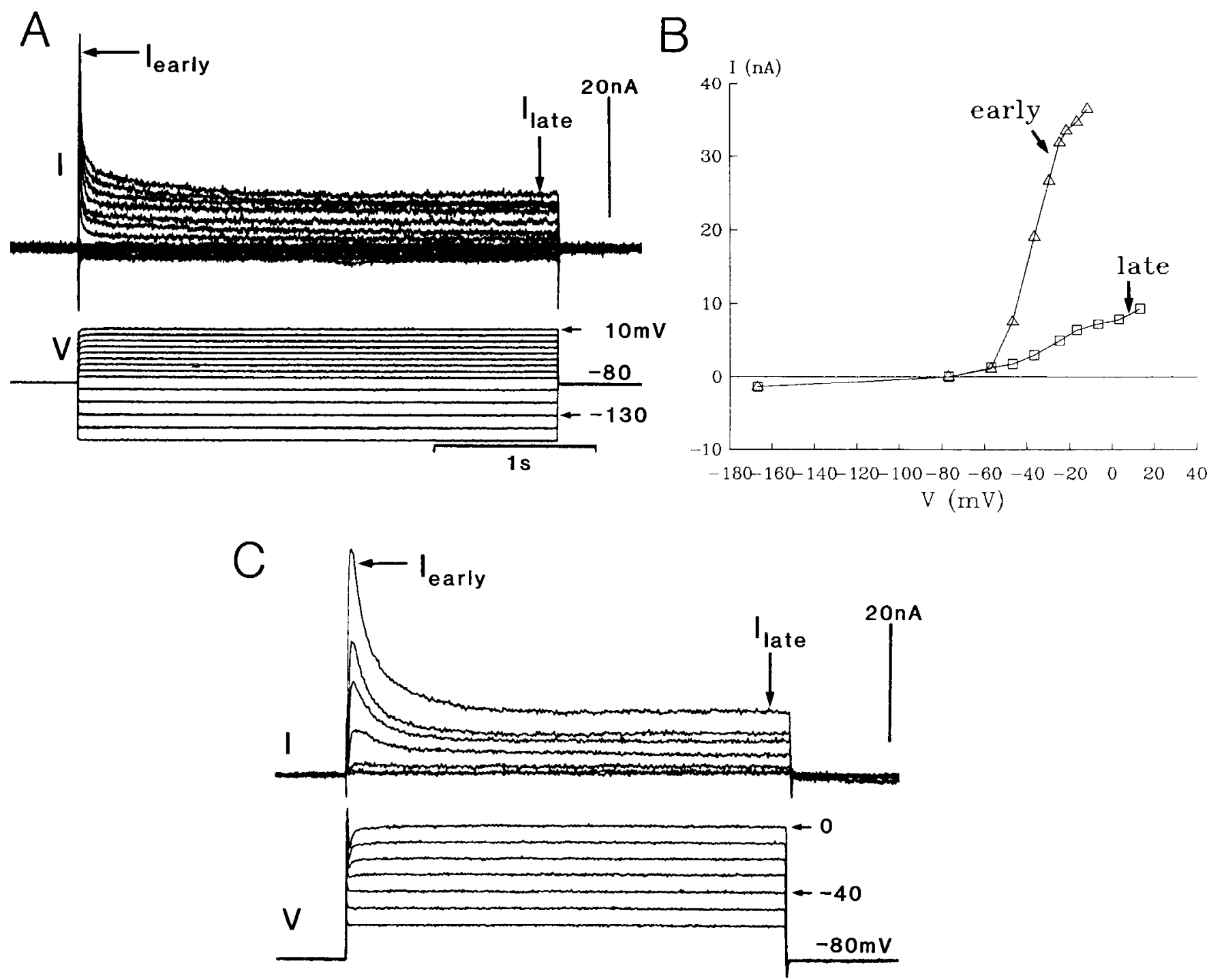

Figure 4. Outward current recordings obtained in single-electrode voltage-clamp conditions. $A$, Currents activated by long-duration depolarizing and hyperpolarizing steps to the indicated levels, from a holding potential of $-80 \mathrm{mV}$. The response to depolarization is a fast inactivating outward current $\left(I_{\text {early }}\right)$ and a sustained current $\left(I_{\text {late }}\right)$. Leak not subtracted. $B$, Plot of the total currents, measured 3 msec $\left(I_{\text {early }}\right)$ and 3 sec $\left(I_{\text {late }}\right)$ after the onset of the voltage steps in $A$. Because of the speed and gain limitations of the single-electrode voltage-clamp, the currents are plotted against the actual recorded potential, measured from the bottom traces in $A$, rather than against the command voltage. $C$, Shorter depolarizing steps (150 msec) delivered to another interneuron, from a holding potential of $-80 \mathrm{mV}$. The current traces have here been leak-subtracted. The inactivation time constant of the early current is less than $20 \mathrm{msec}$. Note that the voltages at which the outward currents start to activate in these 2 nonspiking interneurons differ by $10-15 \mathrm{mV}$.

at which the response drops to half its peak value) increased as the interneuron was further depolarized, by a factor of 9 over $30 \mathrm{mV}$ (Fig. $5 B$ ). No band-pass filter properties were revealed by depolarizing the membrane in this range of voltages. Depolarization of the interneurons thus led to a significant improvement of their frequency response, directly relevant to the fact that they receive both spike-mediated (Burrows, 1987; Burrows et al., 1988; Laurent and Burrows, 1988, 1989a, b) and graded (Burrows, 1979b) synaptic inputs.

\section{Active and graded depolarizing responses}

In about $60 \%$ of recordings, an active response could be evoked by depolarization under the appropriate conditions. In Figure $6 A$, for example, a $2 \mathrm{nA}$ peak-to-peak triangular current was injected into an interneuron from a resting potential of -57 $\mathrm{mV}$. The membrane rectified during the depolarizing half-cycle and behaved quasilinearly below $-65 \mathrm{mV}$. An active depolarizing response appeared at the end of the repolarization, however, as the rate of depolarization increased from about -57 $\mathrm{mV}$, and led to a potential overshoot (arrow, Fig. 6A). In a second experiment, an interneuron was depolarized by a slowly increasing DC current from a resting potential of $-69 \mathrm{mV}$, while short test pulses of $+5 \mathrm{nA}$ were delivered at regular intervals (Fig. 6B). As the membrane potential decreased, the depolarizations evoked by the test pulses diminished in amplitude, because of the membrane rectification (arrow 2, Fig. 6B). At a given "threshold" potential, however, a fast depolarizing transient appeared at the beginning of each test pulse, reaching a peak amplitude at least twice that of the steady-state test depolarization (arrows 3 and 4, Fig. 6B). The 4 pulses indicated in Figure $6 B$ have been expanded and superimposed in Figure $6 C$. The first pulse showed a fast initial rate of depolarization, followed 

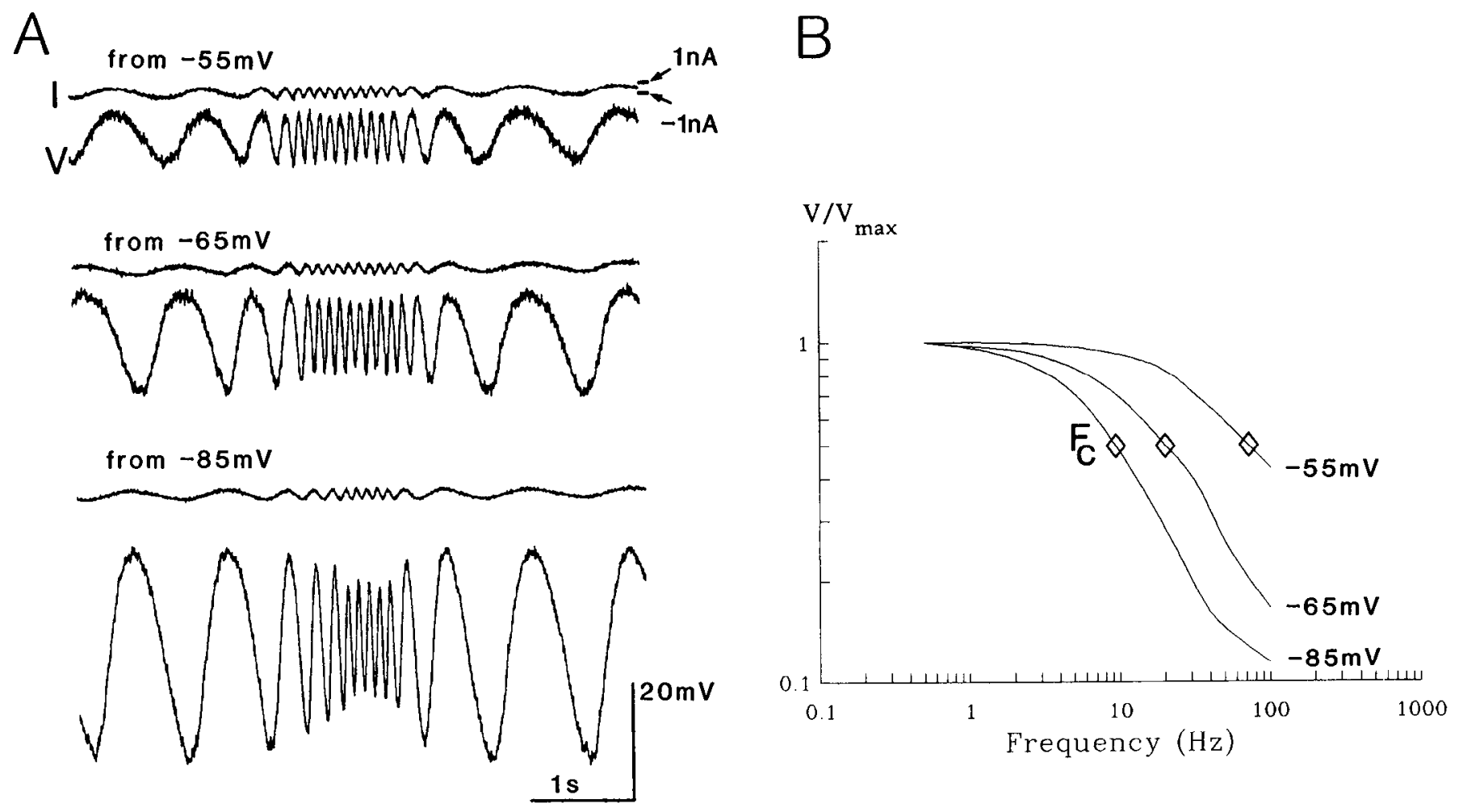

Figure 5. "Dynamic impedance" of the nonspiking interneurons as a function of membrane potential. $A$, Three examples of the variation of voltage with sinusoidal current at 3 different "holding" potentials. $B$. The peak-to-peak voltage over peak-to-peak current at all sampled frequencies has been normalized and plotted against current frequency for the 3 initial membrane voltages $(-55 \mathrm{mV},-65 \mathrm{mV}$, and $-85 \mathrm{mV})$. The measure of peak-to-peak voltage for each frequency was taken and averaged over 30 cycles. Note that the cutoff frequency $\left(F_{\mathrm{c}}\right)$ increases by a factor of 9 over $30 \mathrm{mV}$.

by a slower phase and a plateau. Pulse 2 showed a small transient upon depolarization, and pulses 3 and 4 showed a larger, faster rising transient, followed by a "dip" before reaching steady state (Fig. 6C). Perfusion of $1-10 \mu \mathrm{M}$ TTX in the saline for over 15 min failed to abolish these transients (Fig. 6D). TTX did, however, have access to the neuropilar recording sites as it abolished all spiking activity in the ganglion. In some instances, larger amounts of injected current led to damped oscillations of the membrane voltage, suggesting that the transients are shaped by at least 2 interacting conductances (Fig. $6 E$ ). The rate of repolarization was seen to increase, as larger transient amplitudes were reached (Fig. 6E).

The amplitude of a depolarizing transient depended on the history of stimulation. The interneuron in Figure $6 F$ was first held at $-90 \mathrm{mV}$ for $10 \mathrm{sec}$ and rapidly repolarized to $-50 \mathrm{mV}$. A train of 5.0 depolarizing test pulses was then immediately delivered (5 $\mathrm{nA}$ amplitude, $10 \mathrm{msec}$ duration, $150 \mathrm{msec}$ interpulse interval). The first evoked transient had an amplitude of $28 \mathrm{mV}$ and was followed by a fast repolarization to $-50 \mathrm{mV}$, despite the continuing applied current. The transients evoked later reached lower peak amplitudes and repolarized less. The 40 th transient, for example, had an amplitude of only $10 \mathrm{mV}$, and the membrane only repolarized to $-45 \mathrm{mV}$ (Fig. $6 F$ ).

\section{Voltage dependence of postsynaptic responses}

The occurrence of IPSPs evoked by tonically spiking local interneurons (Burrows, 1987) was used to assess the effects of the membrane rectification on voltage transients caused by synaptic conductance changes. The interneuron in Figure $7 A$ had a "resting" potential of about $-55 \mathrm{mV}$. As the membrane was suc- cessively depolarized to $-41 \mathrm{mV}$ and $-35 \mathrm{mV}$ by current injection, the time course of the IPSPs decreased, reflecting, at least partly, the decrease in membrane time constant (Fig. 7A). Hence, while the IPSPs summated at "resting" potential and prevented the membrane from reaching a steady state, they became so fast at lower potentials that they could only interact if their frequency was increased (Fig. 7A). A second interneuron with a background of IPSPs expressed a strong early rectification upon depolarization (Fig. $7 B$, asterisk) caused by a large A-conductance increase (voltage-clamp data not shown). During the first $50 \mathrm{msec}$ of the depolarizing pulse, the increase in input conductance was greatest, and the IPSPs were totally shunted (Fig. $7 \mathrm{~B}$, asterisk). Then, a second pulse was delivered, $15 \mathrm{msec}$ after the end of the first one. During this second pulse, the membrane reached its steady depolarized level quickly, presumably because the A-conductance had not fully recovered from inactivation (Fig. $7 B$, star). Consequently, the shunting of the IPSPs that had occurred in the first pulse was not repeated (Fig. $7 \mathrm{~B}$, star). A slow triangular current waveform was injected in a third interneuron with a tonic background of IPSPs and held at $-46 \mathrm{mV}$ (Fig. $7 \mathrm{C}$ ). The IPSPs almost disappeared during the depolarization, but reappeared during the hyperpolarizing phase of the waveform (Fig. $7 C$, dots), indicating that the membrane resistance depends not only on the absolute value of the transmembrane potential, but maybe more importantly, on the dynamic characteristics of the voltage change.

Similar experiments were conducted with EPSPs. Mechanosensory afferents from the leg were stimulated in intact animals, and the variations of their direct postsynaptic effects (Laurent and Burrows, 1988) with postsynaptic voltage were studied. The 

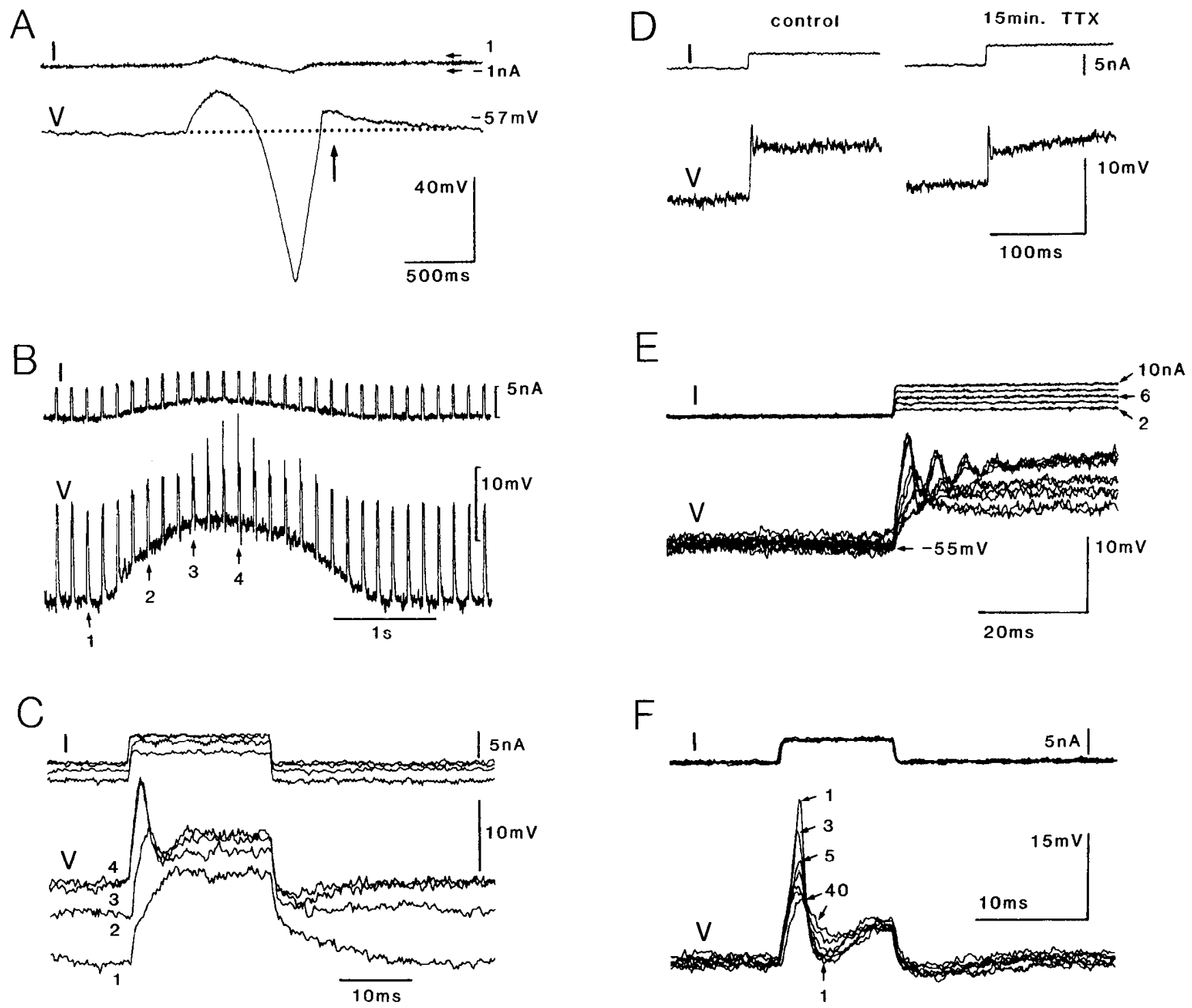

Figure 6. Active depolarizing component. A, Overshoot of the membrane potential at the end of the repolarizing phase of a triangular current waveform (arrow). Note the increase in the rate of the depolarization preceding the overshoot when the membrane crosses $-57 \mathrm{mV}$ (dotted line) and the rectification during the depolarizing phase of the waveform. $B$, Short depolarizing test current pulses are delivered to a nonspiking interneuron held at "resting" potential. A slow depolarizing current is then superimposed. This evokes the appearance of fast depolarizing transients at the start of each voltage charging curve. Test pulses $1-4$ are expanded in $C$. $C$, The 4 pulses indicated in $A$, on an expanded time scale. Note the graded nature of the transient. $D$, The depolarizing transients are not abolished $15 \mathrm{~min}$ after the addition of $10 \mu \mathrm{M}$ TTX. $E$, Large currents sometimes evoke damped oscillations of the membranc potential. $F$, Dependence of the active depolarization on past history. The 1st, 3rd, 5th, 13th, 22nd, and 40 th of a series of 50 test pulses delivered at $6.6 \mathrm{~Hz}$ are superimposed, showing the decrease in peak amplitude and rate of repolarization with time.

interneuron in Figure $8 \mathrm{~A}$ received a direct excitatory input from afferents of tibial mechanoreceptors. These afferents were stimulated electrically en passant from their axons with a suction electrode, and the evoked compound PSP was recorded intracellularly at voltages between -48 and $-95 \mathrm{mV}\left(V_{\mathrm{r}}=-60 \mathrm{mV}\right.$, Fig. $8 A$ ). At "resting" potential, the compound EPSP was monophasic, reached a peak amplitude of ca. $3 \mathrm{mV}$, and decayed to initial voltage in about $20 \mathrm{msec}$. When the interneuron was held hyperpolarized, the EPSP showed an increased amplitude and a slower decay. When the interneuron was held depolarized, the EPSP became smaller, decayed faster (about $5 \mathrm{msec}$ ), and was followed by a slower hyperpolarization. The biphasic appearance of this PSP could be explained in several ways: (1) The afferent-evoked PSP had both excitatory and inhibitory com- ponents, because the electrical stimulus was not specific, and excited afferents from both the excitatory and inhibitory regions of the receptive field (Burrows et al., 1988; Laurent and Burrows, 1988). Depolarization of the interneuron decreased the depolarizing driving force but increased the hyperpolarizing one. (2) The PSP, although only caused by excitatory afferent synapses, was due to coexisting multicomponent synaptic conductances (e.g., Kehoe, 1972). (3) The PSP was purely excitatory, but the synapses were distributed over the arbor of the interneuron. Depolarizing current from the microelectrode reversed the nearest EPSPs but failed to reverse those evoked further away. (4) The EPSP evoked at the most depolarized levels activated a voltage-sensitive conductance, whose battery was negative to the holding voltage. To remove at least the ambiguity of the 
A
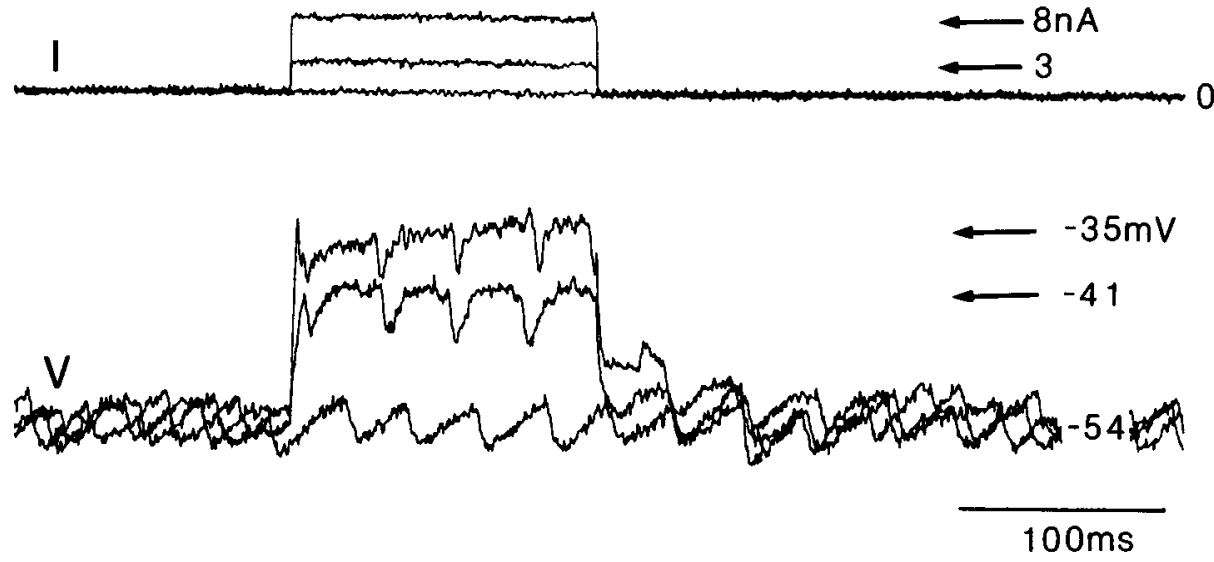

Figure 7. Influence of membrane potential on the integration of IPSPs. $A$, Depolarizing an interneuron to the indicated voltages decreases the decay time constant of IPSPs caused by tonically active presynaptic spiking local interneurons. $B$, Two depolarizing current pulses, separated by $15 \mathrm{msec}$, are injected into a different nonspiking interneuron. The first charging transient is made of a fast spike-like component (arrow), followed by a slow depolarization (asterisk) before steady state. The tonic IPSPs are shunted during the slow depolarization (asterisk). During the steady state, the IPSPs are smaller and faster than when at rest, indicating a maintained input conductance increase as in $A$. The beginning of the second charging curve lacks the fast transient and the slow depolarization (star), and the IPSPs are not shunted. $C, \mathrm{~A} 1 \mathrm{~Hz}$ triangular $8 \mathrm{nA}$ peak-to-peak current waveform is injected into a 3 rd interneuron, held at $-46 \mathrm{mV}$. The tonic IPSPs are very much reduced during the ascending phase of the waveform and reappear during the hyperpolarizing phase (dots), indicating the importance of the dynamic characteristics of the voltage change. Note that the outward rectification occurs here around $V_{\text {r. }}$.

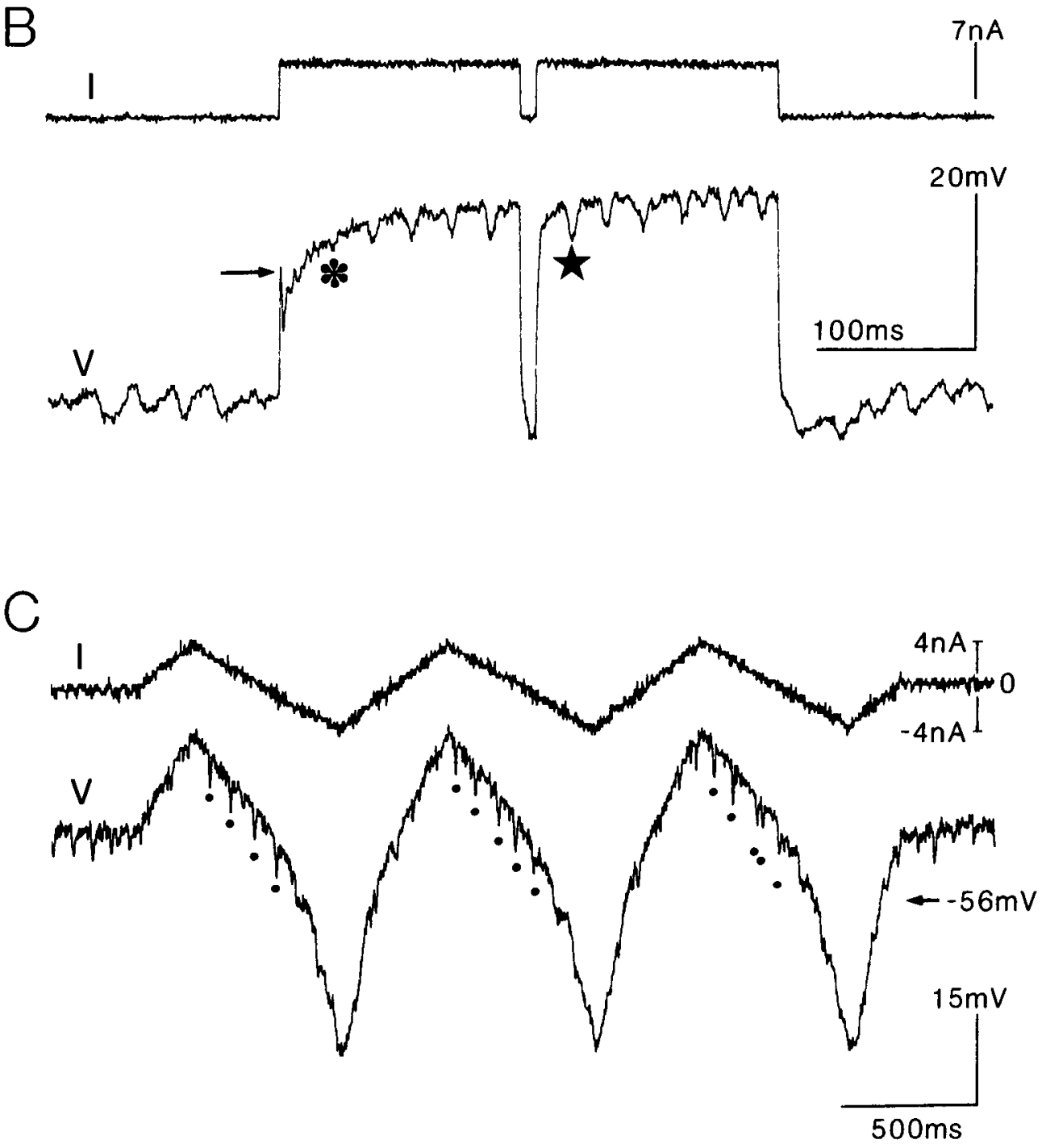

first interpretation, the same experiment was repeated, by stimulating a single presynaptic afferent mechanically, thus precluding a convergence of excitation and inhibition. In such an experiment, hyperpolarizing the interneuron while exciting the single presynaptic afferent had dramatic effects on the time course of the EPSP (Fig. $8 B$ ). Whereas the peak amplitude of the EPSP only increased by a factor of 2 between -50 and $-93 \mathrm{mV}$, the half-width of the EPSP increased by a factor of 7.5 (Fig. 8, $B$, 
A

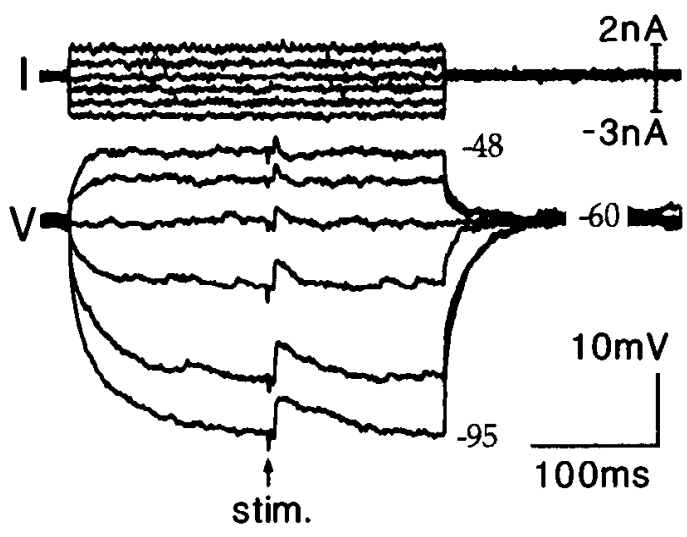

C

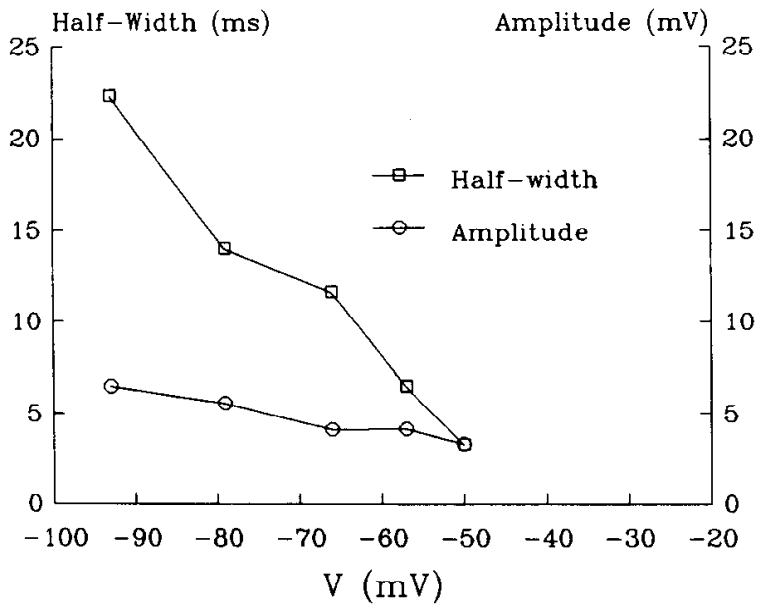

$\mathrm{mV}$
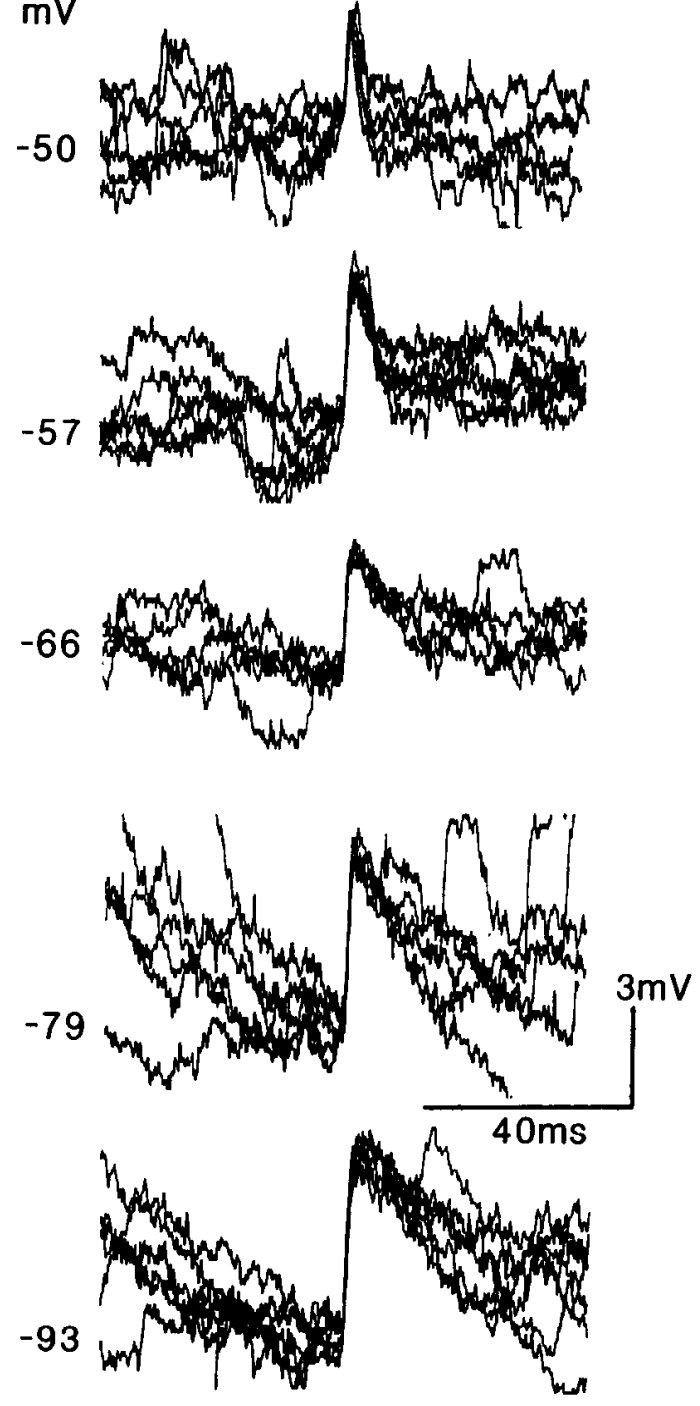

Figure 8. Influence of the membrane potential on the time course and shape of EPSPs evoked by presynaptic hair afferents. A, Compound EPSPs evoked by electrical stimulation of a bundle of hair afferent axons. The time constant of decay of the EPSP increases as the interneuron is hyperpolarized and decreases as it is depolarized. Each trace is an average of 4 sweeps. stim., Stimulus artifact. $B$, The same cxpcrimcnt is performcd with a different interneuron, but the EPSPs are evoked by mechanical stimulation of a single presynaptic afferent. The membrane potential at which each EPSP is evoked is indicated. The voltage traces were aligned at the point of sharp onset of the EPSPs. $C$, The half-width (width at half amplitude) and peak amplitude of the EPSPs in $B$ are plotted as a function of initial membrane potential.

$C$ ). The time constant of decay of the EPSP at hyperpolarized potentials was close to the membrane time constant of the interneuron.

\section{Discussion}

\section{Isolated versus intact preparation}

The average membrane potential of the nonspiking interneurons in the isolated ganglion $(-58.5 \pm 5.8 \mathrm{mV}, n=85)$ was significantly more than the value reported by Burrows and Siegler (1978) from recordings in the intact animal (mean of $-47.7 \pm$ $0.5 \mathrm{mV}$, range -60 to $-35 \mathrm{mV}$ ). As pointed out by these authors, these values cannot be considered "resting" potentials, for the interneurons were under a constant barrage of PSPs, whose multiple origin has now been partially determined (Burrows, 1987; Burrows et al., 1988; Laurent and Burrows, 1988,
$1989 \mathrm{a}, \mathrm{b})$. In the isolated preparation used here, all sensory nerves had been sectioned, which presumably suppressed all tonic afferent activity. The difference between the membrane potentials recorded in the 2 preparations thus probably results from the different balance of excitation and inhibition.

The present value of the mean input resistance of the nonspiking interneurons $\left(R_{\mathrm{IN}}=16.5 \mathrm{M} \Omega\right)$ also significantly differs from that estimated by Burrows and Siegler (1978), who used double electrode penetrations. Their low value of 3-5 $\mathrm{M} \Omega$, given as a minimum estimate, can be explained by at least 3 factors: (1) A large synaptic conductance increase, due to the constant synaptic bombardment of the interneurons. (2) A voltage-dependent conductance increase, due to a lower membrane potential, and to the resulting outward rectification (possibly accompanied by some other noninactivating depolarizing conductance). (3) A large leak conductance, caused by the double 
electrode penetration. The values of $V_{\mathrm{r}}$ and $R_{\mathrm{IN}}$ provided here are thus probably closer to the actual "resting" or passive values, but should still, however, be considered possible underestimates.

\section{Are nonspiking neurons electrically "compact"?}

The finding that the time constant of voltage decay was significantly less for pulses applied from rest than for ones applied from higher potentials indicated that the "resting" membrane cannot be regarded as passive. The passive membrane time constant had to be estimated from regions of linear slope resistance, i.e., generally more negative than $-70 \mathrm{mV}$, using low currents. Exponential fitting of the voltage transients in these conditions, however, consistently yielded at least 2 time constants, indicating charge redistribution on the membrane capacity, and thus nonisopotentiality of the interneurons. Rall $(1969,1977,1989)$ developed a theoretical framework for analysis of the cable properties of ideal neurons (the "equivalent cylindcr" modcl), where the 2 time constants determined experimentally can be used to give an estimate of the electrotonic length (" $L_{\text {pecl }}$ " Fleshman et al., 1988) of the cylinder with sealed ends most nearly equivalent to the whole neuron. $L_{\text {peel }}$ is given by the equation:

$$
\begin{aligned}
L_{\text {peel }}= & n \cdot \pi \cdot\left[\operatorname{tau}_{0} / \operatorname{tau}_{n}-1\right]^{-1 / 2}, \\
& \text { where } n>0
\end{aligned}
$$

which, if applied to the present values of $\operatorname{tau}_{0}$ and tau ${ }_{1}$, gives an average value of $1.04 \pm 0.17$ ( $n=18$ interneurons, range 0.69 $1.5)$. These low values of $L_{\text {peel }}$ suggest that the nonspiking interneurons are electrotonically rather compact. The equivalent cylinder model is, however, valid only under very limited conditions. In particular, the dendritic branching of the neuron must obey the 3/2 power rule (Rall, 1977), $R_{\mathrm{m}}$ and $R_{\mathrm{i}}$ (internal resistivity) must be constant throughout the cell, and all terminal branches must be at the same clectrotonic distance $(L)$ from the point of current application. None of these 3 conditions are known to be valid for nonspiking local interneurons. First, the diameter of a branch at constrictions, swellings, and varicosities (as measured from serially sectioned HRP-filled interneurons observed under the electron microscope; Watson and Burrows, 1988 ) can vary by a factor of $3-4$, suggesting large variations in axial resistance. There is also a great variability in branch point ratios, and the extent of branch tapering is unknown. Second, the uniformity of $R_{\mathrm{m}}$ is improbable as, for example, input synapses on a dendrite can have a patchy distribution (Watson and Burrows, 1988). If some of these synapses were tonically active during the experiments, local dendritic shunts can be expected. The results also demonstrate the existence of voltage-activated conductances on the neurites of the interneurons. Whether their distribution is homogeneous and their inactivation complete at potentials higher than $-70 \mathrm{mV}$ rcmains to be shown. Third, the extremely complex arborization patterns of the nonspiking interneurons (Watkins et al., 1985) make it unlikely that all dendrites terminate at equal electrotonic distances from the recording point. The electrotonic length of dendritic terminals of hippocampal neurons and cat $\alpha$-motor neurons, for example, can range from <1 to 9 (Barrett and Crill, 1974; Turner, 1984; Ulhake and Kellerth, 1984). Finally, the point of current injection was always at an unknown neuropilar location, rather than at the soma. The present estimates of $\operatorname{tau}_{\mathrm{m}}, \mathrm{tau}_{1}$, and $L$ are thus to be considered with caution and should not necessarily indicate either that good space clamp of the neurons will always be easily achieved or that nonspiking interneurons operate as single integrative units. The presence of voltage-activated conductances in particular will be extremely important in shaping the electrical geometry of the neurons. Note, however, that single-electrode voltage-clamp of the membrane was possible, which should allow at the very least a qualitative description of these conductances.

\section{Voltage-dependent nonlinearities}

Outward conductances. All recordings showed a consistent outward rectification, associated with a large increase in input conductance and a decreasc in membrane time constant. At rest, the interneurons lie in the nonlinear region of the $I-V$ curve, indicating that the main conductance underlying the rectification is probably not fully inactivated. This was confirmed by the voltage-clamp experiments, demonstrating the presence of a late, noninactivating outward current upon depolarization. These results suggest the presence of a persistent delayed-rectifier polassium conductance (Hodgkin and Huxley, 1952; Rudy, 1988). Slowly inactivating delayed $\mathrm{K}$ channels, which have recently been described in the soma membrane of larval Drosophila unidentified brain neurons in culture (Solc et al., 1987; Byerly and Leung, 1988; Solc and Aldrich, 1988) and in the blowfly photoreceptor and lamina monopolar cell membranes (Hardie and Weckström, 1990; M. Weckström, R. C. Hardie, and S. B. Laughlin, personal communication), are potential candidates for this rectifying conductance.

The current- and voltage-clamp experiments also indicated the presence of a fast inactivating outward conductance, similar to the "A"-type potassium conductance (Hagiwara et al., 1961; Connor and Stevens, 1971). Such currents have been found in the membrane of unidentified embryonic brain neurons of $\mathrm{Dro}$ sophila (Byerly and Leung, 1988; Solc and Aldrich, 1988) and in the membrane of crustacean nonspiking receptor neuron ( $T$ fiber) (Mirolli, 1981), but had not yet been described in identified nonspiking interneurons. Large monopolar cells in the optic lobes of the blowfly appear to be a second type of nonspiking interneurons expressing these conductances (Hardie and Weckström, 1990).

Inward conductances. Transient depolarizing responses similar to those found here have been observed in other nonspiking neurons such as the EX1 neuron in the lobster stomatogastric ganglion (Graubard, 1978) and the crab T-fiber receptor neuron (Roberts and Bush, 1971; Blight and Llinás, 1981; Mirolli, 1981). In the crab T-fiber, Blight and Llinás (1981) attributed the graded spike evoked near the synaptic region primarily to a $\mathrm{Ca}^{2+}$ conductance increase, whereas Bush (1981) and Mirolli (1981) provide evidence for a TTX-sensitive, $\mathrm{Na}^{+}$-mediated depolarizing response in the distal (receptor) end of the fiber. The resistance of the transient to TTX in the present experiments suggests that it is probably mediated by $\mathrm{Ca}^{2+}$. Its dependence on external $\mathrm{Ca}^{2+}$ has, however, not been investigated.

The finding that the repolarization following a transient depended on the peak voltage (Fig. 6) suggests that a hyperpolarizing conductance was possibly involved. This role might be played by an A-type current, but 2-pulse experiments, where the putative A conductance was partially inactivated in the second pulse, did not always reveal a prolonged depolarizing transient (not shown). It is thus possible that the graded spike results from the successive activation of rapidly activating $\mathrm{Ca}^{2+}$ and $\mathrm{Ca}^{2+}$-dependent $\mathrm{K}^{+}$conductances such as those demonstrated in Drosophila muscle (Singh and Wu, 1989). The damped os- 
cillations observed in some interneurons could thus possibly be a manifestation of a phenomenon of electrical resonance similar to that observed in bullfrog and turtle hair cells, where electrical tuning is achieved by interacting $\mathrm{Ca}^{2+}$ and $\mathrm{Ca}^{2+}$-activated $\mathrm{K}^{+}$ conductances (Art and Fettiplace, 1987; Hudspeth and Lewis, 1988). The phenomenon of damped oscillations was, however, rarely observed in nonspiking local interneurons and is unlikely to be functional, as it was only observed upon injection of large currents.

\section{Functional considerations for integration}

Summation and synaptic transfer. A major consequence of the outward rectification is a substantial increase in input conductance and a decrease in the membrane time constant with depolarization. Hence, an EPSP evoked in a nonspiking interneuron held relatively depolarized will generally be smaller and shorter than if the interneuron were more hyperpolarized. The gain at an input synapse to the interneuron will thus be decreased with depolarization. The rate of rise of the EPSP will also possibly increase, as a rapidly activating depolarizing conductance could be recruited. The immediate consequence is that temporal summation on the membrane of the nonspiking interneurons will depend critically on their membrane potential.

Second, Burrows and Siegler (1978) and Burrows (1979b) showed that nonspiking interneurons generally "rest" at potentials close to the threshold for graded transmitter release. They thus lie in a nonlinear region of the sigmoidal synaptic transfer curve, and small changes in resting voltage will greatly affect the dynamic gain (slope of the $d V_{\text {post }} / d V_{\text {pre }}$ relationship) of the synaptic transfer evoked by a given depolarization at this output synapse. Hence, as the nonspiking interneuron is depolarized, 2 counteracting factors come into play: (1) a decrease in the gain of an input synapse, and (2) an increase in the gain of the nonspiking output synapse. Consider a mechanosensory afferent spike that evokes EPSPs in a nonspiking interneuron, which, in turn, inhibit a motor neuron (Burrows, 1979a). The gain of the disynaptic transfer from the afferent to the motor neuron could be maintained relatively constant, irrespective of the state of the interposed nonspiking interneuron, as a result of these countcracting mechanisms. The cxpcrimcntal rcsults obtaincd so far, however, tend to argue against this idea of gain stabilization, for hyperpolarizing the interposed nonspiking interneuron generally leads to a decreased efficacy of the afferent-to-motor neuron disynaptic transfer (Burrows, 1979a; Laurent and Burrows, 1989 b). This observation was made, however, in situations where the nonspiking interneuron was hyperpolarized well below its threshold for transmitter release and would thus be representative of only the most extreme region of its normal operating range.

Transient conductances. The fact that an active depolarization could only be detected in $60 \%$ of the recordings leads to at least 2 possible hypotheses. First, only some of the nonspiking local interneurons may express this conductance. Second, the appropriate channels might not be uniformly distributed over the branches of the interneurons and may only be detected when a recording is made from or near a branch that expresses them. A heterogeneous distribution of calcium conductances or influxes has, for example, been demonstrated in mammalian Purkinje cells (Llinás and Sugimori, 1980; Ross and Werman, 1987; Tank et al., 1988) and in bursting neurons of crab stomatogastric ganglion (Graubard and Ross, 1985; Ross and Graubard, 1989). The function of this active depolarizing conductance in the lo- cust nonspiking local interneurons could thus be to enhance locally the amplitude and help the dendritic spread of certain EPSPs (Clements et al., 1986) or to increase their rate of rise, and thus further counteract the shunting effect of the conductance increase associated with depolarization, by boosting transmitter release.

The present results suggest the existence of an A-type conductance in the membrane of nonspiking local interncurons. Although its voltage activation and inactivation ranges are so far not known with precision, it appears that the current can be activated by depolarization from "resting" potential. This implies that the conductance should be functional, unlike what was suggested for amphibian nonspiking saccular hair cells (Hudspeth and Lewis, 1988) or fly lamina monopolar interneurons (R. C. Hardie and M. Weckström, unpublished observations). A-currents are generally seen either to (1) regulate the firing frequency of spiking neurons, by slowing down the decay of the afterhyperpolarization (Connor and Stevens, 1971; Rogawski, 1985 ), or (2) delay the occurrence of spikes (and thus of an undesirable output) during a sudden depolarization (Byrne, 1980) or (3) generate the action potential repolarization (Belluzzi et al., 1985). Since the locust nonspiking interneurons have so far never been shown to spike in any circumstance, none of these functional interpretations can be upheld. It is possible that this rapidly activating conductance is required to compensate for a slow activation of the delayed rectifier current, or that it contributes to the steady-state outward current, as in Drosophila myotubes (Solc et al., 1987) or rat cerebellar granule cells (CullCandy et al., 1989). The results shown in Figure 7, however, suggest that this conductance may also be involved in the dynamic control of the integration of synaptic potentials - for example, during rhythmic oscillations of membrane potential. This may be of crucial importance in these interneurons, for they receive both graded and spike-mediated synaptic inputs (Burrows, 1979b, 1987; Burrows et al., 1988; Laurent and Burrows, $1988,1989 \mathrm{a}, \mathrm{b})$. A detailed characterization of these voltagesensitive conductances is thus now needed.

\section{References}

Art JJ, Fettiplace R (1987) Variation of membrane properties in hair cells isolated from the turtle cochlea. J Physiol (Lond) 385:207-242.

Barrett JN, Crill WE (1974) Specific membrane properties of cat motoneurones. J Physiol (Lond) 239:301-324.

Belluzzi O, Sacchi O, Wanke E (1985) A fast transient outward current in the rat sympathetic neurone studied under voltage-clamp conditions. J Physiol (Lond) 358:91-108.

Blight AR, Llinás RR (1981) The non-impulsive stretch-receptor complex of a crab: a study of depolarization-release coupling at a tonic sensorimotor synapse. Phil Trans R Soc Lond B 290:219-276.

Bloomfield SA, Sherman SM (1989) Dendritic current flow in relay cells and interneurons of the cat's lateral geniculate nucleus. Proc Natl Acad Sci USA 86:3911-3914.

Burrows M (1979a) Synaptic potentials effect the release of transmitter from locust nonspiking interneurons. Science 204:81-83.

Burrows M (1979b) Graded synaptic transmission between local premotor interneurons of the locust. J Neurophysiol 42:1108-1123.

Burrows M (1987) Inhibitory interactions between spiking and nonspiking local interneurones in the locust. J Neurosci 7:3282-3292.

Burrows M (1989) Processing of mechanosensory signals in local reflex pathways of the locust. J Exp Biol 146:209-227.

Burrows M, Laurent G (1989) Reflex circuits and the control of movement. In: The computing neuron (Durbin R, Miall RC, Mitchison G, eds), pp 244-261. Reading, MA: Addison-Wesley.

Burrows M, Siegler MVS (1976) Transmission without spikes between locust interneurones and motoneurones. Nature 262:222-224.

Burrows M, Siegler MVS (1978) Graded synaptic transmission be- 
tween local interneurones and motoneurones in the metathoracic ganglion of the locust. J Physiol (Lond) 285:231-255.

Burrows M, Siegler MVS (1982) Spiking local interneurons mediate local reflexes. Science 217:650-652.

Burrows M, Laurent G, Field LH (1988) Nonspiking local interneurons receive direct inputs from a proprioceptor and contribute to local reflexes of a locust hindleg. J Neurosci 8:3085-3093.

Bush BMH (1981) Non-impulsive stretch receptors in crustaceans. In: Neurones without impulses (Roberts A, Bush BMH, eds), pp 147176. Cambridge: Cambridge UP.

Byerly L, Leung HT (1988) Ionic currents of Drosophila neurons in embryonic cultures. J Neurosci 8:4379-4393.

Byrne JH (1980) Quantitative aspects of ionic conductance mechanisms contributing to firing pattern of motor cells mediating inking behavior in Aplysia californica. J Neurophysiol 43:651-668.

Clements JD, Nelson PG, Redman SJ (1986) Intracellular tetraethylammonium ions enhance group Ia excitatory postsynaptic potentials evoked in cat motoneurones. J Physiol (Lond) 377:267-282.

Cole KS (1968) Membranes, ions and impulses. Berkeley and Los Angeles: University of California.

Connor JA, Stevens CF (1971) Voltage-clamp study of a transient outward membrane current in gastropod neural somata. J Physiol (Lond) 213:21-30.

Cull-Candy SG, Marshall CG, Ogden D (1989) Voltage-activated membrane currents in cerebellar granule neurones. J Physiol (Lond) 414:179-199.

Finkel AS, Redman S (1984) Theory and operation of a single microelectrode voltage clamp. J Neurosci Methods 11:101-127.

Flcshman JW, Scgcv I, Burke RE (1988) Electrotonic architecture of type-identified alpha-motoneurones in the cat spinal cord. J Neurophysiol 60:60-85.

Graubard K (1978) Synaptic transmission without action potentials: input-output properties of a non-spiking presynaptic neuron. J Neurophysiol 41:1014-1025.

Graubard K, Ross NR (1985) Regional distribution of calcium influx into bursting neurons detected with arsenazo III. Proc Natl Acad Sci USA 82:5565-5569.

Hagiwara S, Kusano K, Saito N (1961) Membrane changes of Onchidi$u m$ nerve cell in potassium-rich media. J Physiol (Lond) 155:470489.

Hille B (1984) Ionic channels of excitable membranes, $426 \mathrm{pp}$. Sunderland, MA: Sinauer.

Hodgkin AL, Huxlcy AF (1952) Currents carried by sodium and potassium ions through the membrane of the giant axon of Loligo. $J$ Physiol (Lond) 116:449-472.

Hoyle G, Burrows M (1973) Neural mechanisms underlying behavior in the locust Schistocerca gregaria. I. Physiology of identified motoneurons in the metathoracic ganglion. J Neurobiol 4:3-41.

Hudspeth AJ, Lewis RS (1988) Kinetic analysis of voltage and iondependent conductances in saccular hair cells of the bull-frog, Rana catesbeiana. J Physiol (Lond) 400:237-274.

Katz B (1949) Les constantes électriques de la membrane du muscle. Arch Sci Physiol 2:285-299.

Kehoe J (1972) The physiological role of three acetylcholine receptors in synaptic transmission in Aplysia. J Physiol (Lond) 225:147-172.

Laurent $G$, Burrows $M$ (1988) Direct excitation of nonspiking local interneurones by cxtcroceptors underlics tactile reflexes in the locust. J Comp Physiol 162A:563-572.

Laurent $G$, Burrows M (1989a) Distribution of intersegmental inputs to nonspiking local interneurons and motor neurons in the locust. $\mathrm{J}$ Neurosci 9:3019-3029.

Laurent G, Burrows M (1989b) Intersegmental interneurons can control the gain of reflexes in adjacent segments of the locust by their action on nonspiking interneurons. J Neurosci 9:3030-3039.

Llinás RR (1988) The intrinsic electrophysiological properties of mammalian neurons: insights into central nervous system function. Science 242:1654-1664.

Llinás RR, Sugimori M (1980) Electrophysiological properties of in vitro Purkinje cell somata in mammalian cerebellar slices. J Physiol (Lond) 305:175-195.

Masland H, Mills JW, Cassidy C (1984) The function of acctylcholine in the rabbit retina. Proc R Soc Lond B 223:121-139.
McCormick DA, Connors BW, Lighthall JW, Prince DA (1985) Comparative electrophysiology of pyramidal and sparsely spiny stellate neurons of the neocortex. J Neurophysiol 54:782-806.

Merickel M (1980) Design of a single electrode voltage clamp. J Neurosci Methods 2:87-96.

Mirolli M (1981) Fast inward and outward channels in a non-spiking neurone. Nature 292:251-253.

Pearson KG, Fourtner CR (1975) Nonspiking interneurons in the walking system of the cockroach. J Neurophysiol 38:33-52.

Rall W (1969) Time constants and electrotonic length of membrane cylinders and neurons. Biophys J 9:1483-1508.

Rall W (1977) Core conductor theory and cable properties of neurones. In: Handbook of physiology. The nervous system, Vol 1, Chap. 3, pp 39-97. Bethesda, MD: Am. Phys. Soc. Section I.

Rall W (1989) Cable theory for dendritic neurons. In: Methods in neuronal modelling (Koch C, Segev I, eds), pp 9-62. Cambridge, MA, London: MIT Press.

Roberts A, Bush BMH (1971) Coxal muscle receptors in the crab: the receptor current and some properties of the receptor nerve fibres. J Exp Biol 54:515-524.

Rogawski MA (1985) The A-Current: how ubiquitous a feature of excitable cells is it? Trends Neurosci 8:214-219.

Ross WN, Graubard K (1989) Spatially and temporally resolved calcium concentration changes in oscillating neurons of crab stomatogastric ganglion. Proc Natl Acad Sci USA 86:1679-1683.

Ross WN, Werman R (1987) Mapping calcium transients in the dendrites of Purkinje cells in the guinea-pig cerebellum in vitro. J Physiol (Lond) 389:319-336.

Rudy B (1988) Diversity and ubiquity of potassium channels. Neurocience 25:729-749.

Sakuranaga M, Naka KI (1985) Signal transmission in the catfish retina. I. Transmission in the outer retina. J Neurophysiol 53:373389.

Siegler MVS (1984) Local interneurones and local interactions in arthropods. J Exp Biol 112:253-281.

Siegler MVS, Burrows M (1984) The morphology of two groups of spiking local interneurones in the metathoracic ganglion of the locust. J Comp Neurol 224:463-482.

Siegler MVS, Burrows M (1986) Receptive fields of motor neurons underlying local tactile reflexes in the locust. J Neurosci 6:507-513.

Singh S, Wu CF (1989) Complete separation of four potassium currents in Drosophila. Neuron 2:1325-1329.

Solc CK, Aldrich RW (1988) Voltage-gated potassium channels in larval CNS neurons of Drosophila. J Neurosci 8:2556-2570.

Solc CK, Zagotta WN, Aldrich RW (1987) Single-channel and genetic analyses reveal two distinct A-type potassium channels in Drosophila. Science 236:1094-1098.

Stewart WW (1978) Functional connections between cells as revealed by dye coupling with a highly fluorescent Naphtalimide tracer. Cell 14:741-759.

Tank DW, Sugimori M, Connor A, Llinás RR (1988) Spatially resolved calcium dynamics of mammalian Purkinje cells in cerebellar slices. Science 242:773-777.

Turner DA (1984) Segmental cable evaluation of somatic transients in hippocampal neurons (CA 1, CA 3 and dentate). Biophys J 46:7384.

UIfhake B, Kellerth JO (1984) Electrophysiological and morphological measurements in cat gastrocnemius and soleus alpha-motoneurones. Brain Res 307:167-179.

Watkins BL, Burrows M, Siegler MVS (1985) The structure of locust nonspiking interneurones in relation to the anatomy of their segmental ganglion. J Comp Neurol 240:233-255.

Watson AHD, Burrows M (1985) The distribution of synapses on the two fields of neurites of spiking local interneurones in the locust. $J$ Comp Neurol 240:219-232.

Watson AHD, Burrows M (1988) Distribution and morphology of synapses on nonspiking local interneurones in the thoracic nervous system of the locust. J Comp Neurol 272:605-616.

Wilson WA, Goldner MM (1975) Voltage clamping with a single microelectrode. J Neurobiol 6:411-422. 